\title{
Pica? Check a hemoglobin. Iron deficiency anemia? Ask about pica
}

\author{
Joe Nemeth ${ }^{1}$. Philippe Hwang ${ }^{2}$ (1) \\ Received: 29 January 2021 / Accepted: 1 April 2021 / Published online: 21 April 2021 \\ (C) The Author(s), under exclusive licence to Canadian Association of Emergency Physicians (CAEP)/ Association Canadienne de Médecine d'Urgence \\ (ACMU) 2021
}

Keywords Emergency medicine $\cdot$ Pica $\cdot$ Xylophagia $\cdot$ Paper-eating $\cdot$ Pediatrics $\cdot$ Iron-deficiency anemia

\section{Introduction}

The craving and consumption of non-nutritive substances or pica often occur with other mental health disorders but can also be associated with nutritionally deficient states $[1,2]$. According to the DSM-V, pica is the action of non-nutritive ingestion that is repeated for a period of at least a month and is developmentally inappropriate [2]. In certain ethnic populations, pica is culturally acceptable and is not considered pathological [2]. The term is derived from "pica-pica," the Latin word for the magpie bird, because of the bird's indiscriminate gathering and eating a variety of objects [2].

Commonly, pica has been reported to occur with ingestion of many substances including earth (geophagy), raw starches (amylophagy), and ice (pagophagia) [1, 2]. However, the phenomenon of xylophagia or paper-eating has not been well reported or studied in the pediatric patient. We report a case of an adolescent female with no prior medical nor psychiatric history presenting with xylophagia whose symptoms resolved following treatment of underlying asymptomatic iron deficiency anemia.

\section{Case presentation}

A previously healthy 15 -year-old female presented to the emergency department (ED) with her parents with a chief complaint of xylophagia. She reported at least a 7-year history of ingesting clean tissue paper with no clear precipitant/

Philippe Hwang

Philippe.hwang@mail.mcgill.ca

1 Department of Emergency Medicine, McGill University, Montréal, QC, Canada

2 Department of Child Psychiatry, Research Institute of the McGill University Health Centre, The Montreal Children's Hospital, Montréal, QC, Canada inciting event. There was no inciting event which made her divulge her eating disorder to her parents after these many years. She was primarily concerned with how her parents might view her if she told them about her pica. Her review of symptoms was unremarkable. She was an active adolescent participating in daily exercise. Her diet was not restrictive. She reported no recent weight gain/loss, menorrhagia, hematemesis, hematochezia, melena or hematuria. Her bowel movements were normal consistency. There was no family history of hereditary hemoglobinopathies.

Her physical exam was unremarkable. Specifically, her height and weight were approximately at 50th percentile and vital signs were normal. Cardio-respiratory, abdominal, and neurologic exams were non-contributory. The patient underwent biochemical and hematological testing to screen for potential nutritional deficiencies which could have explained her eating disorder. The results of her investigations are shown in Table 1.

The patient was made aware of the findings and was discharged on oral iron supplementation with primary care follow up and repeat investigations arranged. On follow up 3 months later, she reported her pica resolved. Her follow up investigations are shown in Table 1.

We believe this is the first published case of a pediatric patient with severe iron deficiency anemia solely accounting for her xylophagia. Although xylophagia may inherently cause nutritional deficiencies, a causative relationship in this case (pica due to iron deficiency anemia) was more likely since her pathologic non-nutritional craving resolved following treatment of her iron deficiency. Furthermore, she was eventually investigated and found to likely have Celiac disease accounting for her severe iron deficiency anemia.

Pica is often seen in mentally or developmentally disabled persons. Studies suggest significant psychiatric comorbidity including autism spectrum disorder, attention-deficit hyperactivity disorder, schizophrenia, and depression could be a significant determinant of pica [2]. The incidence of pica is 
Table 1 Selected lab results pre- and post-treatment with iron supplementation

\begin{tabular}{lllc}
\hline & $\begin{array}{l}\text { Prior to iron treat- } \\
\text { ment }\end{array}$ & $\begin{array}{l}\text { Following iron treat- } \\
\text { ment }\end{array}$ & Reference range \\
\hline Complete blood count & & & \\
White blood cell Count $\left(10^{\wedge} 9 / \mathrm{L}\right)$ & 4.80 & 6.00 & $4.50-13.00$ \\
Hemoglobin (g/L) & $78(\mathrm{~L})$ & 134 & $115-155$ \\
Mean corpuscular Volume (fL) & $56.6(\mathrm{~L})$ & 86.4 & $78.0-98.0$ \\
Platelets $\left(10^{\wedge} / \mathrm{L}\right)$ & 395 & 199 & $140-450$ \\
Iron studies & & & \\
Iron (umol/L) & $2.2(\mathrm{~L})$ & 30.2 & $5.1-31.6$ \\
Serum ferritin (ug/L) & $3.3(\mathrm{~L})$ & & $8.0-200.0$ \\
Serum transferrin (g/L) & 3.69 & 2.54 & $2.00-3.70$ \\
Iron saturation (ratio) & $0.02(\mathrm{~L})$ & $0.47(\mathrm{H})$ & $0.21-0.42$ \\
\hline
\end{tabular}

$\mathrm{H}$-levels higher than the reference range, $\mathrm{L}$-levels lower than the reference range greater in the preschool age-group patient and is thought to decrease with age with only $10 \%$ of children older than 12 years engaging in pica [3].

The efficacy of iron supplementation in abolishing pica associated with iron deficiency states is well-documented. Central nervouse system neurochemical iron-dependent appetite regulation has been previously suggested as a possible mechanism, but there is still little evidence to conclusively confirm this[4]. There is also some evidence linking decreased brain iron specifically to decreased dopamine $\mathrm{D}^{2}$ receptors and a consequent reduction of several central nervous system dopamine-driven behaviors [5]. However, the exact mechanism by which these behaviors develop still remains to be elucidated.

If pica/xylophagia does not resolve with iron supplementation, there is a potential role for psychobehavioral therapies and pharmaceutical treatment options used in other eating disorders such as anorexia and bulimia [5].

In conclusion, eating disorders are frequent occurrence in the ED. However, pica related disorders merit special consideration. Obvious psychiatric and medical conditions should be screened at the intimal ED visit to identify potential easily reversable causes. Conversely, if significant iron deficiency is discovered in a pediatric patient it would be prudent to inquire about pica.

Author contributions Both authors contributed equally to the writing, editing, and review of the manuscript. Both authors have had the opportunity to review the final manuscript and have provided their permission to publish the manuscript in its current form.

Funding No financial support was received by either author in relation to any aspect of the production of this manuscript.

\section{Declarations}

Conflict of interest The authors have no conflicts of interest to disclose.

\section{References}

1. Borgna-Pignatti C, Zanella S. Pica as a manifestation of iron deficiency. Expert Rev Hematol. 2016;9(11):1075-80.

2. Leung AKC, Hon KL. Pica: a common condition that is commonly missed - an update review. CPR. 2019;15(3):164-9.

3. Murray HB, Thomas JJ, Hinz A, Munsch S, Hilbert A. Prevalence in primary school youth of pica and rumination behavior: the understudied feeding disorders. Int $\mathrm{J}$ Eat Disord. 2018;51(8):994-8.

4. Youdim MB. Brain iron metabolism: biochemical aspects in relation to dopaminergic neurotransmission. Second Edition. Vol. In: Lajitha A, ed. Handbook of Neurochemistry, Vol 10: Pathological Chemistry. New York: Plenum Press: Springer Verlag; 1985.

5. Williams DE, McAdam D. Assessment, behavioral treatment, and prevention of pica: clinical guidelines and recommendations for practitioners. Res Dev Disabil. 2012;33(6):2050-7. 